\title{
Cloning of yeast HAP5: a novel subunit of a heterotrimeric complex required for CCAAT binding
}

\author{
David S. McNabb, Yanyan Xing, and Leonard Guarente ${ }^{1}$ \\ Department of Biology, Massachusetts Institute of Technology, Cambridge, Massachusetts 02139 USA
}

\begin{abstract}
The CCAAT-binding factor is a conserved heteromeric transcription factor that binds to CCAAT box-containing upstream activation sites (UASs) within the promoters of numerous eukaryotic genes. The CCAAT-binding factor of Saccharomyces cerevisiae activates the transcription of these genes in response to growth in a nonfermentable carbon source. Previous studies have demonstrated that the HAP2, HAP3, and HAP4 subunits of the yeast CCAAT-binding factor are required for the transcriptional activation of genes containing a CCAAT box. Using the two-hybrid screening method, we have identified an additional component of the CCAAT-binding factor. We present the identification and characterization of a novel gene, HAP5, that encodes an additional subunit of the CCAAT-binding factor required for the assembly and DNA-binding activity of the complex. In a hap 5 mutant, we show that CCAAT-binding activity is abolished in vitro. Furthermore, we demonstrate that purified recombinant HAP2, HAP3, and HAP5 are able to reconstitute CCAAT-binding activity in mobility shift analysis. These data suggest that the HAP2/3/5 heterotrimer represents a unique DNA-binding factor in which all three subunits of the complex are absolutely required for DNA-binding activity.
\end{abstract}

[Key Words: HAP5; CCAAT-binding factor; transcription; Saccharomyces cerevisiae]

Received October 11, 1994; revised version accepted November 10, 1994.

The transcriptional activation of gene expression is mediated by the binding of distinct regulatory factors to specific cis-acting DNA sequence elements, referred to as enhancers or upstream activation sites (UASs), located within the promoters of eukaryotic genes. Many of these transcription factors are composed of multiple polypeptides that interact in a specific manner to form an oligomeric complex that is capable of recognizing specific cisacting DNA sequence elements. Several families of hetero-oligomeric transcription factors have been identified in eukaryotes (McKnight et al. 1987; Olesen et al. 1987; Chodosh et al. 1988a; Curran and Franza 1988; Gerster and Roeder 1988; Landshultz et al. 1988; Preston et al. 1988; Triezenberg et al. 1988; Murre et al. 1989; Wang and Speck 1992). The herpes simplex virus (HSV) activator VP16 forms a complex with cellular DNA-binding proteins, including Oct-1, to activate the transcriptional machinery (McKnight et al. 1987; Gerster and Roeder 1988; Preston et al. 1988). The GA-binding protein (GABP) is a multisubunit DNA-binding protein (LaMarco and McKnight 1989) required for VP16-mediated activation of HSV immediate early genes (Triezenberg et al. 1988). The core-binding protein $|\mathrm{CBP}\rangle$ is a heteromeric DNA-binding complex that promotes T-cell-spe-

${ }^{1}$ Corresponding author. cific expression of several genes (Wang and Speck 1992). The oncogenes fos and jun encode proteins that belong to a class of transcription factors characterized by a leucine zipper dimerization domain (Landshultz et al. 1988), and Fos-Jun heterodimers activate the transcription of growth-promoting genes (Curran and Franza 1988). Members of the helix-loop-helix family also form heterodimers and include myoD and E12, which are involved in the transcription of genes during muscle cell differentiation (Murre et al. 1988).

In the yeast Saccharomyces cerevisiae the CCAATbinding factor has been shown previously to be a heteromeric complex containing HAP2, HAP3, and HAP4 (Olesen et al. 1987; Hahn and Guarente 1988; Forsburg and Guarente 1989). The HAP2, HAP3, and HAP4 genes were identified because mutations in any of these genes abolish the activity of the CCAAT box in vivo, thereby blocking the expression of nuclear genes encoding mitochondrial proteins and preventing the growth of the mutants on lactate medium (Pinkham and Guarente 1985; Pinkham et al. 1987; Hahn et al. 1988; Forsburg and Guarente 1989). In addition, mutations in either HAP2 or HAP3 eliminate the binding of the HAP complex to a CCAAT box-containing probe in mobility shift analysis (Olesen et al. 1987). Through the use of size variants of HAP2 or HAP3, both proteins have been shown to be present in the CCAAT-bound complex (Olesen et al. 
1987) and remain stably associated in the absence of DNA (Hahn and Guarente 1988). Additionally, studies have shown that one molecule of HAP2 is present per HAP complex (Xing et al. 1993).

A third subunit of the complex, HAP4, was found to contain an acidic activation domain (Forsburg and Guarente 1989) that strongly activates transcription when fused to the DNA-binding domain of LexA /Olesen and Guarente 1990). In a strain containing a null allele of hap4, genes containing a CCAAT box are not activated (Forsburg and Guarente 1989; Olesen and Guarente 1990|; however, this defect can be overcome by fusing the activation domain of GAL4 to HAP2 /Olesen and Guarente 1990), indicating that HAP4 is not essential for the binding of the complex to the CCAAT box. Moreover, mobility shift analyses performed with extracts from a $\Delta$ hap 4 strain have shown that the HAP complex can bind to the CCAAT box in the absence of HAP4 (Xing et al. 1993).

S. cerevisiae HAP2 and HAP3 have been shown to be both structurally and functionally conserved over evolution, because the proteins could be exchanged with fractions containing subunits of the mammalian CCAATbinding factor, CP1, to restore DNA binding at the CCAAT box (Chodosh et al. 1988b). Furthermore, homologs of both HAP2 and HAP3 have been isolated from Schizosaccharomyces pombe (Olesen et al. 1991; Xing et al. 1993), mouse (Hooft van Huijsduijnen 1990), and rat (Maity et al. 1990; Vuorio et al. 1990; Maity and de Crombrugghe 1992), whereas a HAP2 homolog has been isolated from human (Becker et al. 1991). The HAP2 homologs have a strongly conserved region of 60 amino acids (Li et al. 1992), and this 60 amino acid core domain of HAP2 has been shown to possess all of the functions of the intact molecule (Olesen and Guarente 1990). Mutational analysis of the HAP2 core region has delimited two adjacent subdomains, an 18 amino acid region required for the assembly of the HAP subunits, followed by a short linker region, and an adjacent 21 amino acid domain necessary for binding to DNA (Olesen and Guarente 1990; Xing et al. 1993). The DNA-binding domain of HAP2 appears to function in concert with a DNA-binding region of HAP3 to recognize the CCAAT box (Xing et al. 1993). The subunit association domain (SAD) of HAP2 has been shown to be sufficient for assembly of the HAP complex in the absence of the DNAbinding domain, because a LexA-HAP2 fusion protein containing only the SAD forms a transcriptionally active HAP complex at a LexA site in vivo (Xing et al. 1994). Mutational studies have defined the residues within the SAD that are required for the assembly of the HAP complex (Xing et al. 1994). These studies indicate that the $\mathrm{SAD}$ is likely to form an $\alpha$-helical structure that mediates the assembly of the HAP complex, and 8 amino acids along one face of the helix appears to dictate the specificity and at least part of the stability of interaction of HAP2 with its interacting partner.

To better examine the protein-protein interactions that are required for the formation of the HAP complex, $H A P 2$ and HAP3 were expressed in Escherichia coli as fusion proteins with glutathione $S$-transferase (GST). Unexpectedly, we found that bacterially produced HAP2 and HAP3 could not reconstitute binding to a CCAAT box-containing probe in DNA mobility shift experiments. Moreover, we found evidence for the existence of a novel HAP subunit in yeast extracts that is required for the assembly of the complex. Using the two-hybrid method, we have cloned the gene encoding this fourth subunit, designated HAP5, and demonstrate that HAP5 is a component of the HAP complex in vivo. In addition, we show that bacterially produced HAP2, HAP3, and HAP5 will reconstitute binding to a CCAAT box probe in vitro. Thus, HAP2/3/5 represent the first heterotrimeric DNA-binding factor in which three subunits of the complex are absolutely required for DNA-binding activity.

\section{Results}

\section{Evidence for the existence of a fourth HAP subunit}

To better understand the protein-protein interactions that are required for the assembly of the CCAAT-binding factor in $S$. cerevisiae, the core domains of HAP2 and HAP3 (Olesen and Guarente 1990; Xing et al. 1993) were expressed in E. coli as GST fusion proteins and purified as described in Materials and methods. Because previous studies have shown that HAP4 is not essential for CCAAT-binding activity (Xing et al. 1993), we wanted to determine whether purified recombinant GST-HAP2 and GST-HAP3 would bind to the CCAAT box in the absence of other cellular factors. Unexpectedly, we found that the recombinant proteins were unable to reconstitute CCAAT-binding activity in DNA mobility shift analysis. To determine whether GST-HAP2 and GST-HAP3 were functionally active proteins, extracts were prepared from the yeast strain JO1-1a (Dhap2) or SHY40 ( $\Delta$ hap3). Previous studies have shown that extracts prepared from either of these strains do not possess CCAAT-binding activity (Chodosh et al. 1988b; Olesen and Guarente 1990; Xing et al. 1993); however, when GST-HAP3 is added to the $\Delta$ hap3 extract (Fig. 1, lane 1) or GST-HAP2 is added to the $\Delta$ hap2 extract (Fig. 1, lane 2) CCAAT-binding activity is restored. These results suggest that the recombinant proteins are functionally active. However, it is conceivable that GST-HAP2 and GST-HAP3 are capable of interacting with the HAP3 and HAP2, respectively, that are present in yeast extracts to reconstitute DNA-binding activity, but GST-HAP2 and GST-HAP3 together are unable to interact with the CCAAT box because of steric problems resulting from the presence of the GST moiety. To address this possibility, GST-HAP2 and GST-HAP3 were added to extracts prepared from yeast strain JO2-1 (shap2, $\Delta$ hap3). The extract alone from JO2-1 does not show CCAATbinding activity (Fig. 1, lane 5), whereas, the addition of GST-HAP2 and GST-HAP3 to the extract restored CCAAT-binding activity (Fig. 1, lane 3). Moreover, the removal of the GST moiety of the fusion proteins, by cleavage with thrombin, did not affect CCAAT-binding activity (Fig. 1, lane 4). Taken together, these data indi- 


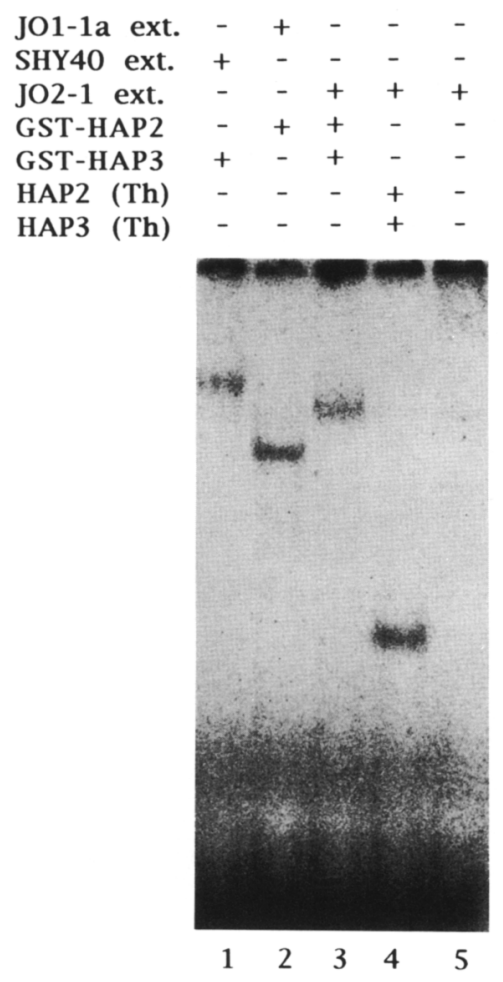

Figure 1. Recombinant GST-HAP2 and GST-HAP3 are functionally active for CCAAT binding. DNA mobility shift assays were performed with DNA-binding reactions containing a radiolabeled CCAAT-box oligonucleotide probe and crude extracts prepared from cells grown in rich glucose medium (YPD). Ex-

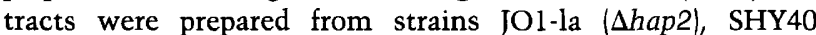

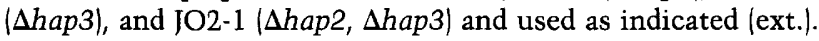
Recombinant GST-HAP2 and GST-HAP3 were added to the DNA-binding reactions as indicated. The recombinant HAP2 and HAP3 proteins in which the GST moiety was removed by thrombin cleavage are designated (Th). The free probe is present at the bottom of the gel.

cate that recombinant $\mathrm{HAP} 2$ and $\mathrm{HAP} 3$ are functionally active and suggests that an additional component(s), present in yeast extracts, is required to reconstitute CCAAT-binding activity.

To gain further insight into the identity of the additional component(s), experiments were performed to determine whether the factor(s) is heat and/or protease sensitive. These studies indicated that the factor(s) present in yeast extracts is sensitive to both heating to $65^{\circ} \mathrm{C}$ for $15 \mathrm{~min}$ and digestion with proteinase $\mathrm{K}$ /data not shown|. These results suggest that the additional component(s) is a protein(s), and this protein(s) appears to be required for the assembly of the CCAAT-binding factor. We shall refer to this additional factor(s) as HAP5 throughout the study.

\section{Isolation of the HAP5 gene by two-hybrid screening}

To isolate the gene encoding the putative HAP5 protein, we utilized the two-hybrid system, a genetic method to identify protein-protein interactions (Fields and Song
1989; Gyuris et al. 1993; Zervos et al. 1993). Because previous studies have shown that the core region of HAP2 (amino acid residues 154-218) is sufficient for the assembly and transcriptional activity of the CCAATbinding factor, the bait for the two-hybrid screen contained codons $154-218$ of $H A P 2$ fused to the first 87 codons of LexA. This plasmid, along with the lacZ reporter plasmid pSH18-34, was introduced into the yeast strain DMY100, an isogenic derivative of EGY48 (Gyuris et al. 1993) containing a hap4 null allele. Because HAP4 contains an acidic activation domain, the deletion of chromosomal HAP4 was necessary to prevent its interaction with the CCAAT-binding factor at LexA sites.

As described in Materials and methods, a galactoseinducible yeast expression library fused to the acidic activation domain $\mathrm{B} 42$ was introduced into strain DMY100 containing the lexA-HAP2 bait, the lacZ reporter plasmid as well as an integrated lexAop-LEU2 allele (Gyuris et al. 1993). The library plasmids were rescued from 20 of the transformants that gave the strongest blue color and $\mathrm{Leu}^{+}$phenotypes, and classified into groups on the basis of both restriction mapping and Southern blot analysis as described in Materials and methods. Two classes of library plasmids, designated p6 and p29, were each obtained five times; whereas, the other 10 library plasmids were all unrelated to these classes or to each other (data not shown). Southern blot analysis with radiolabeled probes specific for either $H A P 2, H A P 3$, or $H A P 4$, also showed that none of the library plasmids contained these genes (data not shown).

Because of the large number of candidate plasmids, we utilized an additional screen to identify the gene encoding HAP5. We hypothesized that the fusion of the B42 activation domain to HAP5 may also restore the transcriptional activity to the CCAAT box-containing reporter plasmid, pLGA265UP1, in strain DMY100 analogous to GAL4 ${ }_{A D}-H A P 2$ (Olesen and Guarente 1990). In addition, we expected the activation of the reporter plasmid to be galactose dependent because the library plasmids are under the control of the galactose-inducible GAL1 promoter. Thus, the 12 classes of potential HAP5encoding plasmids were introduced into strain DMY100 containing the lexA-HAP2 bait and pLG $265 \mathrm{UP1}$, and the resulting transformants were assayed on X-gal medium containing either glucose or galactose as the sole carbon source. One of the library plasmids, designated p92, gave a strong galactose-dependent blue color on X-gal medium (Fig. 2), whereas none of the other plasmids showed a blue color phenotype above background. These data suggest that p92 encodes a protein that is capable of interacting with the CCAAT-binding factor to activate transcription when fused with the acidic activation domain B42.

To map more precisely the site of interaction between the p92-encoded protein and LexA-HAP2, a panel of lexA-HAP2 alleles with stop codon mutations within the DNA-binding domain (DBD) or the SAD were utilized. The p 6 and p29 library plasmids were also included in this series of experiments, as they were obtained repeatedly during the initial screen. The results of these 


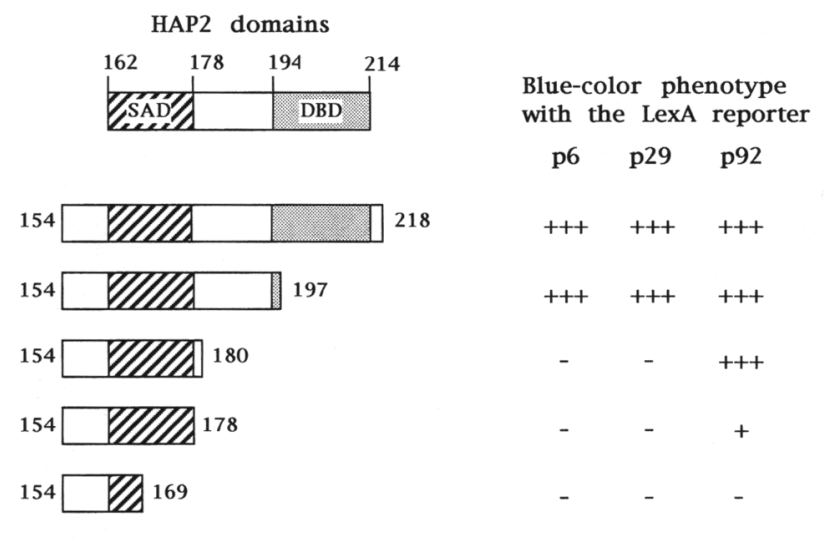

Blue-color phenotype with the CCAAT reporter

$$
\text { p6 p29 p92 }
$$

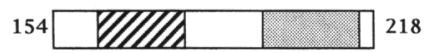

Figure 2. Isolation of the gene encoding HAP5 by two-hybrid screening. A schematic diagram of the LexA-HAP2 baits used for the two-hybrid screen are shown and are described in the text. The hatched and the stippled regions indicate the subunit association domain (SAD) and the DNA-binding domain (DBD) of HAP2, respectively (HAP2 domains), with the numbers above the diagram indicating the amino acid residues encompassing each domain. The numbers to the left and right of each HAP2 bait indicate the amino acid residues of HAP2 that are fused to lexA. (Right) The data obtained with the two-hybrid screen. Strain DMY100 containing the indicated LexA-HAP2 bait, reporter plasmid (either the LexA reporter plasmid pSH18-34 or the CCAAT reporter plasmid pLG $2655 \mathrm{UP} 1$ ), and library plasmid (p6, p29, or p92) were streaked to X-gal medium containing galactose as the sole carbon source. After incubating the strains for 3 days at $30^{\circ} \mathrm{C}$, the blue color phenotype was scored (strong +++ , weak + , none -1 . Five independent transformants of each strain were tested, and all displayed the same phenotype. The strains were streaked in parallel to X-gal medium containing glucose, and none displayed a blue color phenotype /data not shown).

analyses are summarized in Figure 2. All three library plasmids encoded proteins that interacted equally with LexA-HAP2(154-218) and LexA-HAP2(154-197) to give a strong galactose-dependent blue color phenotype on $\mathrm{X}$-gal (galactose) medium; however, only the p92-encoded protein was able to interact with LexAHAP2(154-180) and weakly with LexA-HAP2(154-178). In contrast, none of the proteins interacted with LexAHAP2(154-169). These results suggest that the proteins encoded by $\mathrm{p} 6$ and p 29 require amino acid residues located in the linker region between the DBD and the SAD for interaction with HAP2, whereas the protein encoded by 992 interacts with amino acid residues comprising the SAD (Xing et al. 1993). Because previous studies have shown that specific point mutations within the SAD abolish the assembly of the CCAAT-binding factor, we concluded that the p92 plasmid was likely to contain the gene encoding HAP5.

Previous studies have shown that a yeast strain con- taining a null allele of hap4 is unable to grow on rich medium containing lactate $\left(\mathrm{Lat}^{-}\right)$as the sole carbon source (Forsburg and Guarente 1989); however, the growth defect could be partially bypassed by fusing the GAL4 activation domain to HAP2 (Olesen and Guarente $1990)$. Because the p92-encoded protein was capable of activating the CCAAT box-containing reporter plasmid, pLGA265UP1, we anticipated that the B42-HAP5 chimera might complement a strain containing a hap4 null allele for growth on lactate medium. Thus, the B42HAP5 gene fusion was transferred to the expression plasmid pDB20 (Becker et al. 1991) and introduced into either strain BWG1-7a (HAP4) or SLF401 (Dhap4). As shown in Figure 3, the B42-HAP5 chimera bypassed the need for HAP4 and allowed partial growth of SLF401 on lactate medium suggesting that this gene encodes a newly defined component of the CCAAT-binding factor that we designate HAP5.

\section{Cloning and characterization of the full-length HAP5 gene}

The sequence of the partial HAP5 open reading frame was obtained from the library plasmid p92. DNA se-

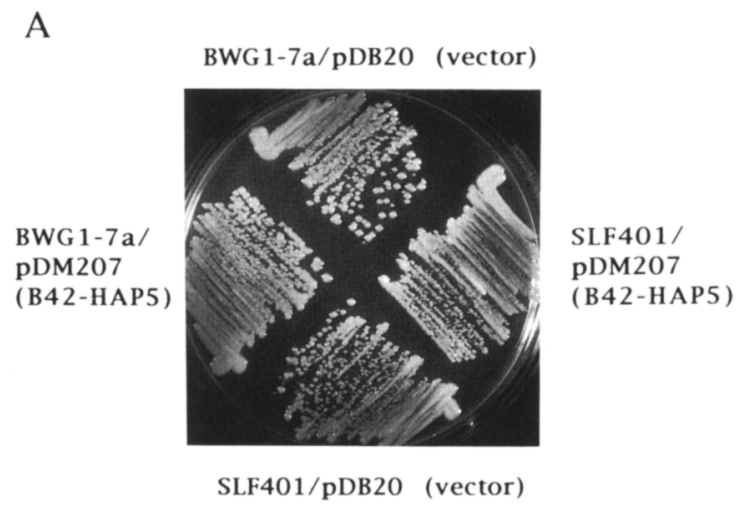

B

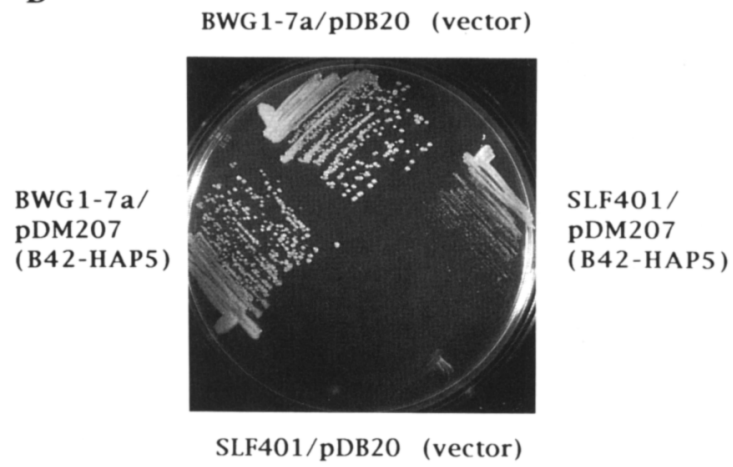

Figure 3. B42-HAP5 chimeric protein partially complements the Lat ${ }^{-}$phenotype of a yeast strain containing a $\Delta$ hap 4 allele. Yeast strains BWG1-7a (HAP4) and SLF401 (Shap4) were transformed with either plasmid pDB20 (vector only) or pDM207 (expressing the B42-HAP5 gene fusion) and streaked to rich glucose medium (YPD) $(A)$ and rich lactate medium $(\mathrm{YPL})(B)$ as indicated. The strains were subsequently incubated at $30^{\circ} \mathrm{C}$ for 3 days. 
quence analysis revealed that the clone encodes the carboxy-terminal 163 amino acid residues of HAP5 fused to B42. On the basis of the results presented in the previous section, these data suggest that this region of HAP5 suffices for its interaction with the CCAAT-binding factor in vivo.

Previous studies have demonstrated that mutants containing a null allele of hap2, hap3, or hap4 are unable to grow on medium containing lactate as the sole carbon source (Pinkham et al. 1987; Hahn et al. 1988; Forsburg and Guarente 1989). To determine whether hap5 mutants displayed a similar phenotype, the 850 -bp yeast genomic DNA fragment from p92 was used to construct a disrupted allele of the HAP5 gene by insertion of the hisG-URA3-hisG cassette at a BglII site within the HAP5-coding region. The disrupted allele of HAP5 was introduced into strain BWG1-7a, and $\mathrm{Ura}^{+}$transformants were selected. Six independent transformants were streaked to 5-FOA medium to obtain $\mathrm{Ura}^{-}$derivatives, and Southern blot analysis was performed to verify that the disruption occurred at the HAP5 locus (data not shown). The transformants were subsequently tested for their ability to grow on lactate medium. As shown in Figure 4, DMY110 (hap5::hisG) grew normally on glucose-containing (YPD) medium (Fig. 4A), but was unable to grow on lactate-containing (YPL) medium (Fig. 4B). These results indicate that a hap 5 null mutant has a

A

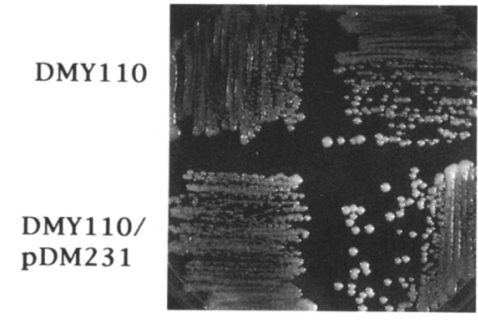

BWG 1-7a

B

DMY110

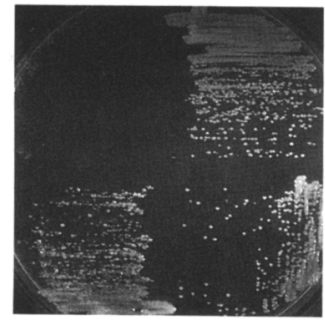

BWG 1-7a

DMY110/

DMY110 pDM231

pDM233
Figure 4. A yeast strain containing a hap 5 null allele is unable to grow on medium containing lactate as the sole carbon source. Yeast strains BWG1-7a (HAP5) and DMY110 thap5::hisG), along with DMY110 (hap5::hisG) transformed with either plasmid pDM231 /containing the 4.2-kb genomic clone isolated by complementation of the $\mathrm{Lat}^{-}$phenotype) or pDM233 (a 1.4-kb subclone of pDM231 that fully complements the Lat ${ }^{-}$phenotype) were streaked to rich glucose medium $(A)$ and rich lactate medium $(B)$ as indicated. The strains were subsequently incubated at $30^{\circ} \mathrm{C}$ for 3 days. The isolation of pDM231 and the construction of pDM233 are described in Materials and methods.
Lat $^{-}$phenotype similar to that of hap2, hap3, and hap4 mutants.

The Lat ${ }^{-}$phenotype of the hap 5 null strain provided a convenient selection by which to isolate the full-length HAP5 gene. Thus, DMY110 (hap5::hisG) was transformed with a low-copy yeast genomic library and selected for growth on lactate medium. Seven independent $\mathrm{Lat}^{+}$transformants were obtained. To verify that the Lat $^{+}$phenotype was conferred by a plasmid-encoded gene, the transformants were streaked on 5-FOA medium to select for plasmid loss, and the $\mathrm{Ura}^{-}$segregants were retested for growth on lactate medium. All seven transformants concomitantly lost the $\mathrm{Ura}^{+}$and $\mathrm{Lat}^{+}$ phenotypes, demonstrating that the library plasmid was required for complementation. From the seven transformants, two unique clones were isolated, and restriction mapping showed that one of the clones contained a 10$\mathrm{kb}$ genomic insert and the other a $4.2-\mathrm{kb}$ genomic fragment that overlapped entirely with the larger insert. A 1.4-kb SstI fragment was identified within the $4.2-\mathrm{kb}$ clone that fully complemented the Lat $^{-}$phenotype of DMY110 (Fig 4). Using the internal fragment of the HAP5 gene as a probe, the HAP5 genomic locus was physically mapped by hybridization to an ordered set of $\lambda$ clones of the yeast genome lobtained from the ATCC; Riles et al. 1993). These results indicated that HAP5 is on the right arm of chromosome XV near and centromere-proximal to the PHR1 gene (data not shown).

The complete nucleotide sequence and the predicted amino acid sequence of the HAP5 gene are shown in Figure 5. The HAP5 open reading frame predicted a protein of 216 amino acid residues, giving an estimated molecular weight of 24,863. Analysis of the predicted amino acid sequence of HAP5 showed no obvious structural motifs and no significant homology to protein sequences present in the data base.

\section{HAP5 is a component of the CCAAT-binding factor}

We constructed a size variant of HAP5 to determine whether the protein is a component of the CCAAT-binding factor. The size variant of HAP5 used in these experiments was a GST-HAP5 fusion protein expressed in $E$. coli and purified as described in Materials and methods. As controls, GST, GST-HAP2 and GST-HAP3 were prepared in an identical manner. Yeast extracts prepared from strain BWG1-7a (wild type) grown in lactate medium were used in combination with the purified recombinant proteins in DNA mobility shift assays (Fig. 6). The extract alone revealed two distinct complexes, designated complex I and II, with a CCAAT box-containing probe (Fig. 6, lane 2), and these complexes have been shown previously to contain HAP2/3 and HAP2/3/4, respectively (Xing et al. 1993). Addition of purified GST to the extracts did not alter the mobility of the complex (Fig. 6, lane 5), indicating that the GST moiety does not interact with the CCAAT-binding factor. When GSTHAP2 (containing the HAP2 core domain) was included with the extract, an additional species of complex I and II, was observed (Fig. 6, lane 3), whereas the presence of 


\begin{abstract}
1 TGMAGAAATCCCGAAATGTCAAAATCGAAGAGTGTTGTGCTCCCTTTTCCGTAGTTAAACTTA 64 AATTTGCGTGGGACGGCTCCCTTAAGATTGCTTCCGGAGATTAAGCTTCCTTAGCTGCTATAA 127 TACCGCGTAAGCAAAGAAGAAGATAGAGGGGATAGGAGATAATGTAAGAGTTGTGACGCAT 190 TTGCAGCATCAGGATTGTTTACTCGCATAATGACTGATAGGATTTCTCACCACAACAAGGAC 253 AAGGACCTCAAGAATCGCTCCGGAGGGACCGCAACCCAGTACG ATG ATT CAG AGA GAG 311 GAA ATG AAT ATG CCA AGG CAA TAT TCA GAA CAG CAA CAA CTG CAA GAA

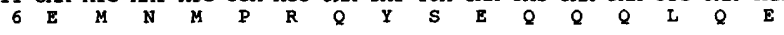

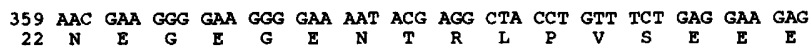
407 TTC CGG ATG GTA CAG GAG TTG CAA GCT ATC CAG GCG GGC CAT GAC CAA 55 GCT

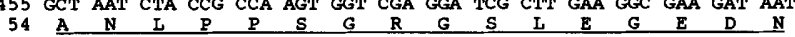
503 GGA AAC AGC GAC GGC GCA GAC GGA GAA ATG GAC GAG GAC GAT GAA GAG

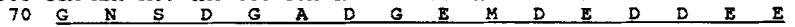
551 TAT GAT GTG TTT AGG AAC GTT GGT CAG GGA TTG GTG GGC CAC TAC AAG $\begin{array}{lllllllllllllllll}86 & \underline{Y} & D & V & F & R & N & V & G & O & G & L & V & G & H & Y & K\end{array}$ 599 GAG ATA ATG ATC CGT TAT TGG CAA GAA TTA ATC AAC GAG ATC GAG TCT

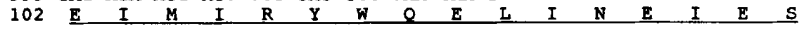
647 ACG AAT GAA CCT GGT TCC GAG CAT CAA GAT GAC TTC AAA TCA CAT TCC

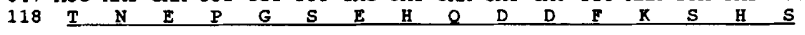
695 TTA CCA TTT GCG AGA ATC CGC AAG GTC ATG AAG ACG GAT GAA GAT GTC

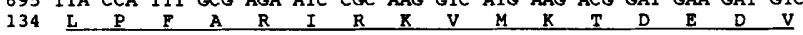
743 AAG ATG ATT AGT GCA GAG GCC CCC ATC ATT TTC GCC AAA GCC TGT GAC

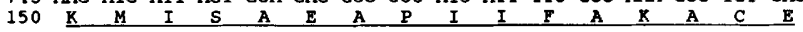
791 ATC TTT ATT ACA GAA CTG ACT ATG AGA GCT TGG TGC GTG GCA GAA AGG

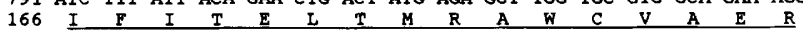
839 AAT AAA AGA CGA ACT TTG CAG AAG GCA GAT ATC GCA GAG GCC CTG CAA

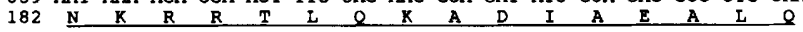
887 AAG AGT GAC ATG TTT GAC TTT CTC ATC GAT GTT GTG CCT AGA AGA CCT

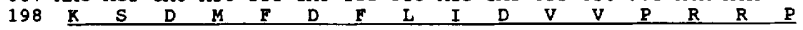
935 CTT CCA CAA TGA GAGAGTTAATGGTTATACAGCTGCCATTTGACCGTGCACCACAGCAA 214 L P Q *

994 ATTATCTGTTGGAAAAAGAAAAACGCAAATTTTTTCATTATTTTTTTCCAGAATAAGTTTG 1057 GTAGCAAATTGGCGATGAGATATCTAACAACGACTACTACTACTACCATAGGATTGTCTCGAA 1120 TACTTGTGTTTGCAGT
\end{abstract}

Figure 5. Sequence of the HAP5 gene and predicted amino acid sequence. Sequencing was performed using the Sequenase/ dideoxy chain termination method on Bluescript $\mathrm{KS}(+1-)$ or $\mathrm{SK}|+1-|$ phagemids carrying restriction fragments of HAP5 or using custom synthetic oligonucleotide primers. The putative initiator methionine is shown in boldface type and underlined. The region of HAP5 fused to the acidic activation domain B42 in the $\mathrm{p} 92$ clone is underlined.

GST-HAP3 resulted in an additional complex I band (Fig. 6, lane 4). When GST-HAP5 was added to the extract an additional form of both complex I and II was observed (Fig. 6, lane 6), demonstrating that HAP5 is a component of the CCAAT-binding factor. Moreover, because the $3^{\prime} 163$ codons of HAP5 were used to construct the GST-HAP5 fusion, these data suggest that the carboxy-terminal 163 amino acid residues of HAP5 are sufficient for its interaction with CCAAT-binding complexes I and II. It should be noted that a more slowly migrating form of complex II was not observed with the addition of GST-HAP3. The significance of this observation is currently unclear but may indicate that GSTHAP3 is unable to effectively exchange with the endogenous HAP3 to form complex II.

\section{HAP5 is required for the assembly of the CCAAT- binding factor}

The above experiments show that HAP5 is a component of the CCAAT-binding factor; however, they do not address the functional role of HAP5 in the heteromeric complex. It is conceivable that HAP5 may be required for DNA-binding activity, similar to HAP2 and HAP3 (Olesen et al. 1987). Alternatively, HAP5 may be necessary for some step in transcriptional activation subsequent to DNA binding, analogous to HAP4 (Forsburg and Guarente 1989). To determine whether HAP5 is required for CCAAT-binding activity, DNA mobility shift assays were performed with extracts prepared from either strain DMY110 (hap5::hisG) or BWG1-7a (HAP5) grown in rich glucose medium (YPD). As shown in Figure 7, extracts prepared from DMY110 did not show CCAAT-binding activity (Fig. 7, lane 5), indicating that HAP5 is essential for the assembly and/or DNA-binding activity of the complex. As a control, extract from BWG1-7a was analyzed in parallel and clearly demonstrated CCAAT-binding activity (Fig. 7, lane 2). The addition of purified GST to the DMY110 extract failed to restore CCAAT-binding

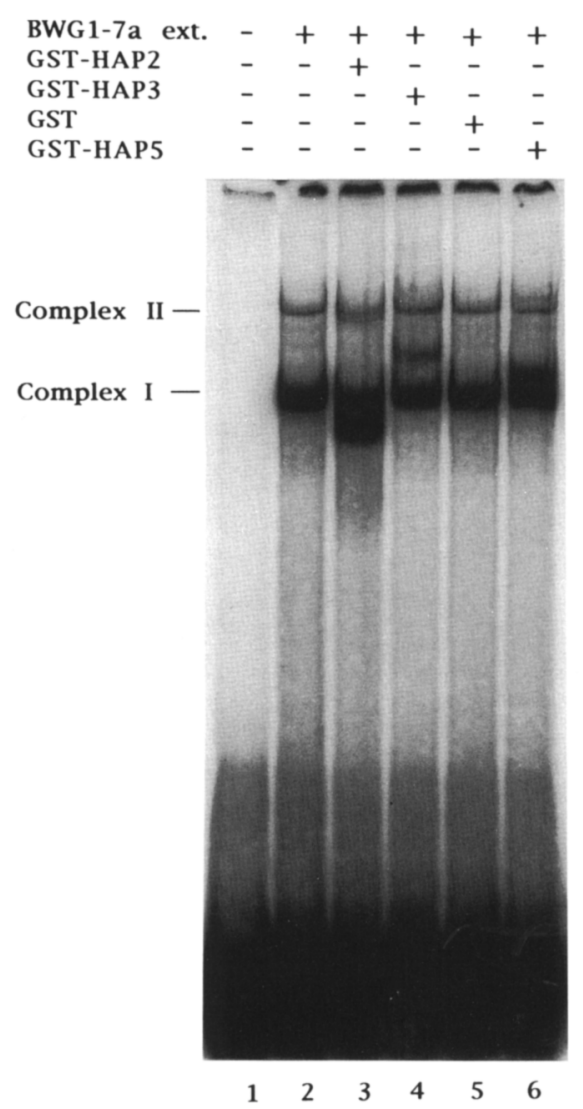

Figure 6. HAP5 is a subunit of the CCAAT-binding factor. DNA mobility shift assays were carried out with DNA-binding reactions containing a radiolabeled CCAAT box oligonucleotide probe incubated with crude yeast extracts prepared from strain BWG1-7a grown in rich lactate medium (BWG1-7a ext.). Purified recombinant GST, GST-HAP2, GST-HAP3, or GSTHAP5 was added to the DNA-binding reactions as indicated. The complexes shown previously to contain HAP2/3 /complex I) and HAP2/3/4 (complex II) are labeled. Lane 1 is a control reaction containing the CCAAT-box probe alone. 


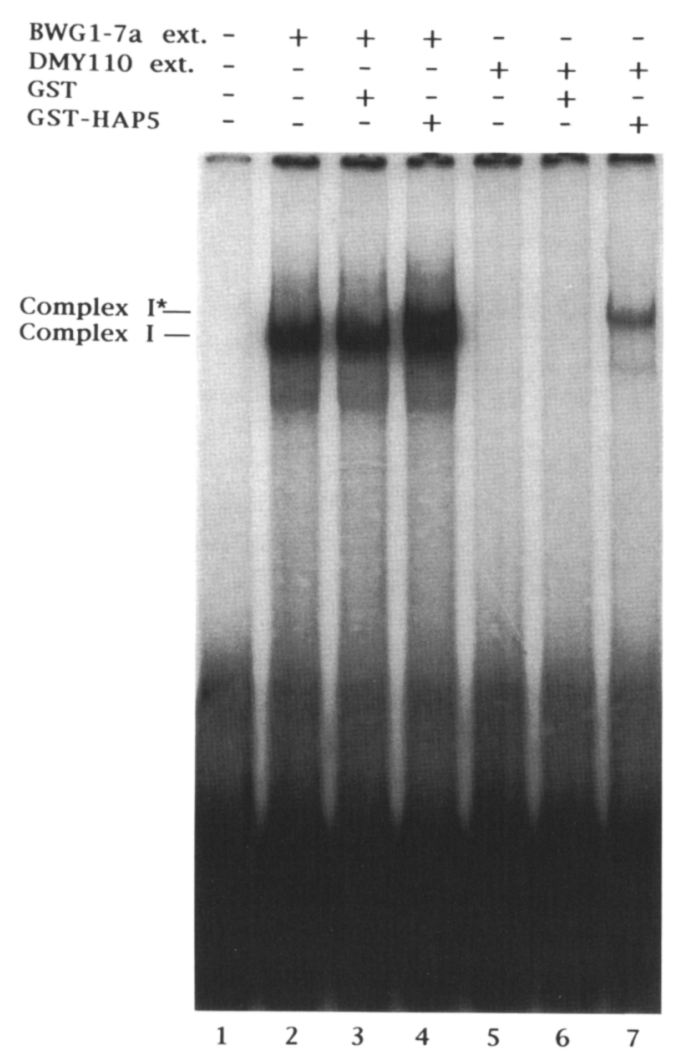

Figure 7. HAP5 is required for the assembly of the CCAATbinding factor. DNA mobility shift assays were performed with DNA-binding reactions containing a radiolabeled CCAAT box probe incubated with crude yeast extracts (ext.) prepared from strains BWG1-7a (HAP5) or DMY110 (hap5::hisG) as indicated. For preparation of extracts, the strains were grown in rich glucose medium. Purified recombinant GST or GST-HAP5 were included in the DNA-binding reactions as indicated. The complexes containing HAP2/3/5 (complex I) and HAP2/3/GSTHAP5 (complex $I^{\star}$ ) are labeled. As a control, the binding reaction in lane 1 contains the unbound probe.

activity; however, adding GST-HAP5 to the extract reconstituted the activity (Fig. 7, lane 7). Moreover, the mobility of the complex was identical to that obtained by adding GST-HAP5 to the BWG1-7a extract (Fig. 7, lane 4). On the basis of these results, we conclude that HAP5 is required for the assembly and/or DNA-binding of the CCAAT-binding factor.

\section{Reconstitution of the CCAAT-binding activity from recombinant GST-HAP2, GST-HAP3, and GST-HAP5}

The previous results have demonstrated that HAP5 is associated with the CCAAT-binding factor and is required for the assembly of the heteromeric complex at the CCAAT box; however, they do not prove that HAP5 is the only additional factor required for assembly and DNA binding. To address this point, mobility shift studies were performed using a CCAAT box-containing probe and various combinations of purified recombinant
GST, GST-HAP2, GST-HAP3, and GST-HAP5 (Fig. 8). These data demonstrate that the individual HAP subunits are unable to bind to the CCAAT box (Fig. 8, lanes $1-3)$. In addition, the various combinations of two HAP subunits cannot reconstitute CCAAT-binding activity (Fig. 8, lanes 4-6). CCAAT-binding activity is detected only when GST-HAP2, GST-HAP3, and GST-HAP5 are present in the DNA-binding reactions (Fig. 8, lane 8). Furthermore, GST alone cannot substitute for GSTHAP5 (Fig. 8, lane 7), demonstrating that the HAP5 moiety is required to reconstitute DNA-binding activity. Thus, these data demonstrate that HAP2, HAP3, and HAP5 are the only components of the CCAAT-binding factor that are required for the assembly and binding of the complex to DNA in vitro.

\section{Discussion}

We described the identification of the HAP5 gene, encoding a novel component of the yeast CCAAT-binding factor, which is required, along with HAP2 and HAP3, for assembly of a heterotrimeric DNA-binding factor that binds to the CCAAT box. The HAP2/3/5 complex is novel in that all three subunits are absolutely essential for DNA-binding activity. This is in contrast to other multimeric transcriptional activators such as the herpes simplex virus trans-activator protein VP16-induced complex (McKnight et al. 1987; Gerster and Roeder 1988; Kristie et al. 1989; Katan et al. 1990; Xiao and Capone 1990), the interferon-stimulated gene factor-3

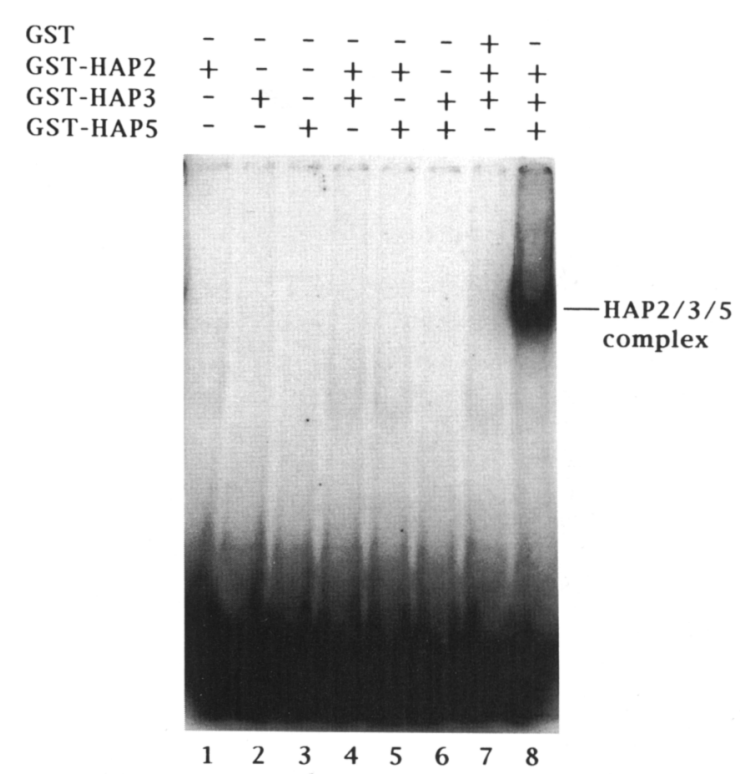

Figure 8. Reconstitution of CCAAT-binding activity with recombinant GST-HAP2, GST-HAP3, and GST-HAP5. DNA mobility shift assays were performed with DNA-binding reactions containing a radiolabeled CCAAT-box probe incubated with purified recombinant GST, GST-HAP2, GST-HAP3, and GST-HAP5 in the various combinations indicated. The free probe migrates to the bottom of the gel. The position of the HAP2/3/5 complex is shown at right. 
(ISGF-3) complex (Kessler et. al. 1988; Levy et al. 1988, 1989; Dale et al. 1989), the GABP complex (Triezenberg et al. 1988; LaMarco and McKnight 1989/, or the CBP complex (Wang and Speck 1992), which contain a single subunit that is capable of binding to specific DNA sequence elements in the absence of the other components. In the case of the VP16-induced complex, a single subunit of the complex, the octamer-binding protein Oct-1, has been shown to bind specifically to the sequence ATGCTAAT that comprises a portion of the ATGCTAATGARAT sequence recognized by the VP16-induced complex (Kristie and Sharp 1990; Stern and Herr 1991). The interaction between Oct-1, VP16, and a host cell factor (HCF) aids in the recruitment of Oct-1 to the ATGCTAATGARAT sequence (Cleary et al. 1993) located in the upstream promoter regions of the immediate early genes of HSV-1 (O'Hare and Goding 1988; Preston et al. 1988). In the case of ISGF-3, the $48-\mathrm{kD}$ subunit has been shown to bind specifically to the IFN-stimulated response element (ISRE) in the absence of the other subunits, Stat $1 \alpha$, Stat $1 \beta$, and Stat2; however, the presence of the Stat subunits increases the affinity of this DNAprotein interaction (Fu et al. 1990; Kessler et al. 1990). Analogously, the GABP and the CBP DNA-binding complexes contain one subunit that binds to specific DNA sequence elements, and the additional subunits increase the affinity of the DNA-protein interaction (Thompson et al. 1991; Wang et al. 1993).

HAP5 was isolated by the two-hybrid method using the essential core sequence of HAP2 as bait. A $\Delta$ hap 5 strain cannot use lactate as a carbon source, a phenotype shared by hap2, hap3, and hap 4 mutants (Pinkham et al. 1987; Hahn et al. 1988; Forsburg and Guarente 1989). HAP5 encodes a protein containing 216 amino acids with no obvious structural motifs or sequence homology to known gene products. Thus, the mechanism of assembly of the HAP subunits and their binding to DNA is likely to be novel. CCAAT-binding complexes I and II, containing HAP2/3 and HAP2/3/4 (Xing et al. 1993), respectively, also contain HAP5. Thus, complex II bound at the CCAAT box consensus site is a heteromeric complex containing at least four subunits, whereas complex I contains a minimum of three subunits.

What is the functional role of HAP5 in the CCAATbinding factor? On the basis of mutational studies of both HAP2 and HAP3 (Xing et al. 1993, 1994), we suggested previously that the HAP2 and HAP3 proteins interact through two distinct domains: (1) a weak interaction between the DNA-binding domains of HAP2 and HAP3; and (2) a strong interaction between the SADs. Once HAP2 and HAP3 are brought together by SADs, the weak interaction between the DNA-binding domains creates a hybrid structure capable of recognizing the CCAAT box. The results from the two-hybrid data suggest that HAP5 interacts with HAP2 through the SAD. Thus, we suggest that HAP5 is the linchpin that binds to the SADs of both HAP2 and HAP3 to bring the proteins together, thereby allowing the weak interaction between the HAP2/3 hybrid DNA-binding domain to occur. Consistent with this model is the fact that an extract pre- pared from a hap5 null strain lacks CCAAT-binding activity, but the activity is restored by the addition of recombinant HAP5.

Is the HAP5 subunit of the CCAAT-binding factor evolutionarily conserved? Although, comparison of the predicted amino acid sequence of HAP5 with the current data base did not reveal any proteins with significant homology, HAP5 is likely to be conserved because the SAD of HAP2, required for its interaction with HAP5, shows a high degree of evolutionary conservation (Li et al. 1992). Furthermore, studies with the rat CCAATbinding complex (CBF) suggest that three components, designated $\mathrm{CBF}-\mathrm{A}, \mathrm{CBF}-\mathrm{B}$, and $\mathrm{CBF}-\mathrm{C}$, are required for the assembly of the CCAAT-binding complex in vitro (Maity et al. 1992). CBF-C might represent the mammalian counterpart of HAP5.

It should also be noted that two additional library plasmids, referred to as $\mathrm{p} 6$ and $\mathrm{p} 29$, were obtained from the two-hybrid screen. The proteins encoded by these plasmids bound to sequences including the linker region of HAP2. It is possible that these genes encode factors that are required for the assembly of the complete CCAATbinding factor; alternatively, they may encode ancillary factors required for transcriptional activation by the CCAAT-binding factor.

In summary, we describe a novel DNA-binding factor that binds to the CCAAT box and contains three essential subunits, $\mathrm{HAP} 2 / 3 / 5$. To our knowledge, this is the first example of a DNA-binding complex with three essential subunits. In contrast, other factors involved in signal transduction, such as G-proteins, are typically found as heterotrimers. It will be of interest to see whether other newly discovered transcription factors require three subunits for DNA binding and whether the trimeric nature of such factors serves an important functional role.

\section{Materials and methods}

Strains

Yeast strain BWG1-7a (MATa, ura3-52, leu2-3,112, his4-519, ade1-100; Guarente and Mason 1983) and its isogenic derivatives, SLF401, (Ahap4::LEU2; Forsburg and Guarente 1989), JO1-la (Shap2; Olesen and Guarente 1990), SHY40

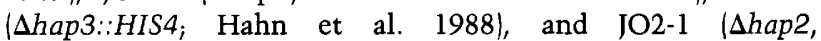
$\Delta$ hap3::HIS4; Olesen and Guarente 1990) were used in these studies. Strain DMY110 is an isogenic derivative of BWG1-7a containing the hap5::hisG allele. The disrupted allele of HAP5 was constructed by transferring the 850-bp HAP5-containing EcoRI fragment from p92 to the EcoRI site of Bluescript KS +. The resulting plasmid, pDM208, was digested with BglII and ligated with the BamHI-BglII hisG-URA3-hisG cassette from pNKY51(Alani et al. 1987). This plasmid, pDM212, was subsequently digested with EcoRI and introduced into BWG1-7a, selecting for $\mathrm{Ura}^{+}$transformants. The $\mathrm{Ura}^{+}$transformants were streaked to rich lactate medium to score the growth phenotype. Transformants having a Lat $^{-}$phenotype were patched onto 5-FOA plates to select for $\mathrm{Ura}^{-}$derivatives of the strains (Sikorski and Boeke 1991). Yeast strain DMY100 (MATa, trp1, ura3, his3, LEU2::pLexAop6-LEU2, Dhap4::hisG) is an isogenic hap $4^{-}$derivative of EGY48 (a kind gift from Roger Brent, Mas- 
sachusetts General Hospital, Boston; Gyuris et al. 1993) that was used as a host for the two-hybrid screen. The disrupted allele of HAP4 was constructed using the plasmid pKS::HAP4 $\Delta$ hisG (kindly provided by P. Sugiono, unpubl.) that contains the his $G-U R A 3-$ his $G$ cassette inserted between the $5^{\prime}$ ClaI site and the BglII site of HAP4. The plasmid was digested with SacI-NotI and introduced into EGY48 by selecting for $\mathrm{Ura}^{+}$transformants. The transformants were subsequently screened as described above, and $\mathrm{Ura}^{-}$derivatives were selected on 5-FOA medium. All disruptions were confirmed by Southern blot analysis.

\section{Media}

Rich, synthetic omission, and synthetic minimal media were prepared as previously described (Sherman 1991), and supplemented with $2 \%$ glucose, $2 \%$ lactate, or $2 \%$ galactose. Lactate medium (YPL) consists of $1 \%$ yeast extract, $2 \%$ peptone, and $2 \%$ lactate. Medium containing 5-FOA (Sikorski and Boeke 1991) and yeast X-gal medium (Guarente 1983) have been described previously.

\section{Plasmids and plasmid constructions}

The plasmid pLG $\Delta 265 \mathrm{UP} 1$ has been described previously (Guarente et al. 1984). The plasmid pSH18-34 contains a GAL1lac $Z$ reporter with four LexA operator sites at the -167 position relative to the transcriptional start site from GAL1 (a generous gift from Steve Hanes and Roger Brent, Massachusetts General Hospital, Boston). The plasmid pJO323 (Olesen and Guarente 1990) contains the core domain of HAP2 (amino acid residues 154-218) fused to the first 87 codons of lexA. To construct an expression plasmid with a HIS3 marker for the two-hybrid screen, pJO323 was digested with BamHI, and BamHI-BamHI fragment $\mid \mathrm{ADH} 1$ promoter-lexA-HAP2 core-ADH1 terminator) was isolated and ligated into the BamHI site of pRS423 (Christianson et al. 1992) to give the plasmid pDM201. The plasmids pDM202, pDM203, pDM204, and pDM205 contain the HAP2 core domain with stop codons inserted at positions $178,180,169$, and 197, respectively (Olesen and Guarente 1990; Xing et al. 1993; Y. Xing and L. Guarente, unpubl.) as well as the HIS3 marker. They were constructed by digesting the expression plasmids pJO324 (Olesen and Guarente 1990) or pYX3236 (Xing et al. 1994) with SphI and isolating the 1.5-kb fragment containing the HAP2 alleles. These HAP2 alleles were subsequently ligated into the SphI-digested backbone of pDM201, and the correct orientation verified by restriction digestions. The plasmid pDM207 was constructed by digesting p92 with HindIII and transferring the $1.1-\mathrm{kb} B 42-H A P 5$ fragment to the $\mathrm{ADH} 1$ promoter-driven expression plasmid pDB20 (Becker et al. 1991). The GST-HAP5 expression plasmid pDM215 was constructed in two steps. Initially, p92 was digested with EcoRI and the 850-bp fragment encoding HAP5 was isolated and ligated into the EcoRI site of the plasmid pET28a (Novagen). This plasmid pDM210 was subsequently digested with BamHI-HindIII, and the 850-bp fragment containing HAP5 was isolated and ligated into the BamHI-HindIII-digested GST expression plasmid pGEX-KG (Guan and Dixon 1991). To construct the GST-HAP2 expression plasmid pG2C the core region of HAP2 (amino acid residues 158-214) was amplified by PCR using primers that contained BamHI and BgIII sites flanking the $5^{\prime}$ and $3^{\prime}$ ends, respectively. After digestion with BamHI and BglII, the amplified fragment was ligated into the BamHI site of the expression plasmid pGEX-KT (Guan and Dixon 1991), and the correct orientation verified by restriction analysis. To construct the GSTHAP3 expression plasmid $\mathrm{pG} 3 \mathrm{C}_{\text {, }}$ the core region of $H A^{\mathrm{P} 3}$ (amino acid residues 35-127) was amplified by PCR using primers that contained BamHI and BglII sites flanking the $5^{\prime}$ and $3^{\prime}$ ends, respectively. The amplified fragment was cloned into pGEX-KT as described for pG2C. The plasmid pDM231 contains a $4.2-\mathrm{kb}$ genomic fragment encoding HAP5 that was obtained by complementation of the Lat ${ }^{-}$phenotype of DMY110 (hap5::hisG). pDM233 was constructed by ligating the $1.4-\mathrm{kb}$ SstI fragment isolated from pDM231 into the SstI site of pRS316 (Sikorski and Hieter 1989).

\section{Two-hybrid screen for HAP5}

The starting strain for the two-hybrid screen was DMY100 containing the plasmids pDM201 (LexA-HAP2 core domain) and pSH18-34 (LexAop-lacZ reporter). A yeast genomic library fused to the acidic activation domain B42 in the plasmid pJG4-5 (kindly provided by Paul Watt, Harvard University, Cambridge, MA; Gyuris et al. 1993) was introduced into this strain (Gietz et al. 1992), and $\sim 500,000$ transformants were obtained on synthetic minimal medium containing glucose $(\mathrm{SD})+\mathrm{Leu}$. The cells were replica plated to synthetic minimal medium containing galactose (SGal), and after 7 days at $30^{\circ} \mathrm{C}, 778 \mathrm{Leu}^{+}$colonies were collected on SD + Leu master plates. These transformants were subsequently retested on SGal, SD, X-gal (galactose) + Leu, and X-gal (glucose) + Leu plates, and 608 colonies showed galactose-dependent blue color on X-gal plates and a galactose-dependent Leu ${ }^{+}$phenotype. Of these, 20 colonies showing the strongest galactose-dependent blue color and $\mathrm{Leu}^{+}$phenotypes were selected for further analysis. The plasmids were rescued from these colonies (Hoffman and Winston 1987), introduced into $E$. coli PB68 (a kind gift from Rainer Knaus, MIT, Cambridge, MA) by electroporation, and the transformants collected on Trp ${ }^{-}$ ampicillin plates. The plasmids were initially sorted into classes by restriction mapping using EcoRI. This classification was confirmed and further refined by performing Southern blot analysis on the EcoRI-digested plasmids, using a plasmid from each class as the probe. The DNA probes were radiolabeled with $\left[\alpha^{-32} \mathrm{P}\right] \mathrm{CTP}$ using either a nick translation (GIBCO-BRL) or random priming kit (U.S. Biochemical) according to the protocol of the manufacturer. To determine whether any of the plasmids encoded either HAP2, HAP3, or HAP4, the EcoRI-digested plasmids were also analyzed by Southern blotting with HAP2-, HAP3-, and HAP4-specific DNA probes. One representative from each of the 12 classes of library plasmids was subsequently introduced into strain DMY100 containing pDM201 (lexAHAP2 bait) and the CCAAT box-containing lacZ reporter plasmid pLG $\triangle 265$ UP1 as described above. Five independent transformants from each class were streaked to X-gal medium containing either glucose or galactose as the sole carbon source. To test the library plasmids against a panel of LexA-HAP2 baits containing stop codons at various positions within the DBD and SAD of HAP2, strain DMY100 containing the various LexAHAP2 baits and the lacZ reporter pSH18-34 were transformed with the library plasmids and the galactose-dependent blue color scored as described above.

\section{Cloning and sequencing of genomic HAP5}

A low copy genomic library, a generous gift from Craig Thompson (Thompson et al. 1993), was introduced into strain DMY110 (hap5::hisG) using 10 independent transformation reactions as described previously (Gietz et al. 1992), and the $\mathrm{Ura}^{+}$transformants selected on - Ura omission medium. The transformants were subsequently scraped into 10 separate pools and replated on rich lactate medium. Positive $\left(\mathrm{Lat}^{+}\right)$colonies were identified in seven of the pools. The plasmids were rescued (Hoffman and 
Winston 1987) from a single yeast isolate from each pool and introduced into $E$. coli XL1 blue (Stratagene) by electroporation. Subcloning was carried out as described above. Sequencing was performed by the dideoxy chain termination method (Sanger et al. 1977) and the Sequenase system (U.S. Biochemicals). The templates for sequencing were single-stranded phagemids derived from Bluescript $\mathrm{KS}(+/-)$ or $\mathrm{SK} \mid+/-$ ) (Stratagene). Homology searches were performed using the BLAST network service at the National Center for Biotechnology (NCBI).

\section{Expression and purification of GST fusion proteins}

GST fusion protein expression and purification were essentially as described previously (Smith and Johnson 1988). Fresh overnight cultures of $E$. coli DH5 $\alpha$ transformed with either pGEXKG alone or one of the above-mentioned pGEX-KG or pGEX-KT recombinant plasmids were diluted $1: 100$ in terrific broth $(T B)$ (Tartof and Hobbs 1987) containing ampicillin $(100 \mu \mathrm{g} / \mathrm{ml})$ and incubated at $37^{\circ} \mathrm{C}$ with shaking until the cells reach an $\mathrm{OD}_{600}$ of 0.6 . Isopropyl- $\beta-D-$ thiogalactopyranoside (IPTG) was added to a final concentration of $1 \mathrm{~mm}$, and the cells were allowed to incubate for an additional $3 \mathrm{hr}$ at $37^{\circ} \mathrm{C}$ with shaking: For analysis of total bacterial protein, aliquots of each bacterial culture were pelleted at $10,000 \mathrm{~g}$, boiled in SDS-PAGE sample buffer $162.5 \mathrm{~mm}$ Tris- $\mathrm{HCl}$ at $\mathrm{pH} 6.8,2 \% \mathrm{SDS}, 20 \%$ glycerol, $0.3 \mathrm{~m} \beta$-mercaptoethanol, and $0.05 \%$ bromophenol blue), and loaded onto an SDS$10 \%$ polyacrylamide gel. Proteins were visualized by Coomassie blue staining.

For fusion protein purification using glutathione-Sepharose (Pharmacia), bacterial lysates were prepared as described previously (Kaelin et al. 1991). Briefly, the bacterial cultures were pelleted by centrifugation at $5000 \mathrm{~g}$ for $5 \mathrm{~min}$ at $4^{\circ} \mathrm{C}$ and resuspended in $1 / 10$ volume of NETN buffer $(20 \mathrm{mM}$ Tris- $\mathrm{HCl}$ at $\mathrm{pH}$ $8.0,100 \mathrm{~mm} \mathrm{NaCl}, 1 \mathrm{~mm}$ EDTA, $0.5 \%$ NP-40). The bacteria were lysed on ice by mild sonication and centrifuged at $10,000 \mathrm{~g}$ for $5 \mathrm{~min}$ at $4^{\circ} \mathrm{C}$. The resulting supernatant was aliquoted into $1-\mathrm{ml}$ fractions and rocked for $30-45 \mathrm{~min}$ at $4^{\circ} \mathrm{C}$ with $150 \mu \mathrm{l}$ of glutathione-Sepharose, which had been previously washed four times and resuspended ( $50 \% \mathrm{vol} / \mathrm{vol})$ in NETN buffer. The glutathione-Sepharose beads were subsequently pelleted and washed four times with NETN. The GST fusion proteins were eluted from the glutathione-Sepharose beads in a buffer containing $50 \mathrm{~mm}$ Tris- $\mathrm{HCl}(\mathrm{pH} 8.0), 10 \mathrm{~mm}$ glutathione, with $3 \times 3$ min washes in $0.5 \mathrm{ml}$ of buffer. The three washes were pooled and dialyzed overnight against DNA-binding buffer described below. For analysis of protein purification, the resulting products were loaded onto SDS-polyacrylamide gels. Proteins were visualized by Coomassie blue staining.

\section{Preparation of yeast extracts}

Yeast protein extracts were prepared as described previously (Olesen et al. 1987), with some modifications. Cells were harvested at an $\mathrm{OD}_{600}$ value of 1.0 and washed with $1 / 30$ volume of extraction buffer $[200 \mathrm{mM}$ Tris- $\mathrm{HCl}$ at $\mathrm{pH} 8.0,400 \mathrm{~mm}$ $\left(\mathrm{NH}_{4}\right)_{2} \mathrm{SO}_{4}, 10 \mathrm{~mm} \mathrm{MgCl}_{2}, 1 \mathrm{~mm}$ EDTA, $10 \%$ glycerol, $7 \mathrm{~mm}$ $\beta$-mercaptoethanol, $1 \mathrm{mM}$ PMSF, $5 \mathrm{~mm}$ benzamidine, $1 \mu \mathrm{g} / \mathrm{ml}$ of leupeptin, $1 \mu \mathrm{g} / \mathrm{ml}$ of pepstatin). The cell pellet was resuspended in $1 / 500$ volume extraction buffer, and cells were disrupted by agitation at $4^{\circ} \mathrm{C}$ with a vortex mixer in the presence of an equal volume of glass beads $(0.45 \mathrm{~mm}$ diam.). Following incubation for $30 \mathrm{~min}$ at $0^{\circ} \mathrm{C}$, unlysed cells and glass beads were removed by centrifugation at $10,000 \mathrm{~g}$ for $5 \mathrm{~min}$ and the supernatant was then centrifuged at $10,000 \mathrm{~g}$ for $1 \mathrm{hr}$ at $4^{\circ} \mathrm{C}$. The resulting supernatant was removed and the proteins were precipitated by the addition of $100 \%\left(\mathrm{NH}_{4}\right)_{2} \mathrm{SO}_{4}$ in $10 \mathrm{mM}$ HEPES at $\mathrm{pH} 8.0,5 \mathrm{~mm}$ EDTA to a final $\left(\mathrm{NH}_{4}\right)_{2} \mathrm{SO}_{4}$ concentration of $40 \%$. Following incubation for $30 \mathrm{~min}$ at $4^{\circ} \mathrm{C}$ with gentle agitation, proteins were precipitated by centrifugation at $10,000 \mathrm{~g}$ for $10 \mathrm{~min}$ and the pellet was resuspended in DNA-binding buffer $(20 \mathrm{~mm}$ HEPES-NaOH at $\mathrm{pH} 7.9,100 \mathrm{~mm} \mathrm{KCl}, 1 \mathrm{~mm}$ EDTA, 20\% glycerol, $7 \mathrm{~mm} \beta$-mercaptoethanol, $1 \mathrm{mM}$ PMSF, 5 $\mathrm{mM}$ benzamidine, $1 \mu \mathrm{g} / \mathrm{ml}$ of leupeptin, $1 \mu \mathrm{g} / \mathrm{ml}$ pepstatin) and dialyzed against the same buffer before use in DNA-binding reactions.

\section{DNA-binding assays and gel electrophoresis}

The UAS2UP1 probe (CCAAT) was designed as described previously (Hahn and Guarente 1988). The DNA probe was endlabeled by Klenow fragment with $\left[\alpha^{-32} \mathrm{P}\right] \mathrm{dATP}$. All binding reactions contained $20-30 \mu \mathrm{g}$ of yeast extract, $12 \mathrm{~mm}$ HEPES$\mathrm{NaOH}$ (pH 7.9), $60 \mathrm{~mm} \mathrm{KCl}, 4 \mathrm{~mm}$ Tris- $\mathrm{HCl}$ (pH 7.9), $1 \mathrm{~mm}$ EDTA, $12 \%$ glycerol, $4.2 \mathrm{~mm} \beta$-mercaptoethanol, $3.0 \mu \mathrm{g}$ of poly[d(I-C)], $3.0 \mu \mathrm{g}$ of denatured salmon sperm DNA, and 0.5$1.0 \mathrm{ng}$ of the UAS2UP1 probe in a final volume of $10 \mu \mathrm{l}$. Reactions were incubated at $23^{\circ} \mathrm{C}$ for $30-45 \mathrm{~min}$. The protein-DNA complexes were resolved by gel electrophoresis ( $4 \mathrm{hr}$ at $200 \mathrm{~V}$ ) on $5 \%$ polyacrylamide gels (acrylamide to bisacrylamide weight ratio of $37.5: 1)$ in $0.5 \times \mathrm{TBE}$ at $4^{\circ} \mathrm{C}$. After electrophoresis, the gels were fixed, dried, and visualized by autoradiography with Kodak X-OMAT AR film or a PhosphorImager (Molecular Dynamics).

\section{Acknowledgments}

We thank Roger Brent for the yeast strains and plasmids used in the two-hybrid screen, Paul Watt for the two-hybrid yeast genomic library, Craig Thompson and Richard Young for the pCT3 yeast genomic library, and Rainer Knaus for the E. coli PB68 strain. We also thank Roy Pollock for critical reading of the manuscript and members of the laboratory for helpful comments during these studies. This research was supported by postdoctoral fellowship PF-4044 from the American Cancer Society (to D.S.M.) and National Institutes of Health grant GM30454 (to L.G.).

The publication costs of this article were defrayed in part by payment of page charges. This article must therefore be hereby marked "advertisement" in accordance with 18 USC section 1734 solely to indicate this fact.

\section{References}

Alani, E., L. Cao, and N. Kleckner. 1987. A method for gene disruption that allows repeated use of URA3 selection in the construction of multiply disrupted yeast strains. Genetics 116: $541-545$.

Becker, D.M., J.D. Fikes, and L. Guarente. 1991. A cDNA encoding a human CCAAT-binding protein cloned by functional complementation in yeast. Proc. Natl. Acad. Sci. 88: 1968-1972.

Chodosh, L.A., A.S. Baldwin, R.W. Carthew, and P.A. Sharp. 1988a. Human CCAAT-binding proteins have heterologous subunits. Cell 53: 11-24.

Chodosh, L.A., J. Olesen, S. Hahn, A.S. Baldwin, L. Guarente, and P.A. Sharp. 1988b. A yeast and a human CCAAT-binding protein have heterologous subunits that are functionally interchangeable. Cell 53: 25-35.

Christianson, T.W., R.S. Sikorski, M. Dante, J.H. Shero, and P. Hieter. 1992. Multifunctional yeast high-copy-number shuttle vectors. Gene 110: 119-122. 
Cleary, M.A., S. Stern, M. Tanaka, and W. Herr. 1993. Differential positive control by Oct-1 and Oct-2: Activation of a transcriptionally silent motif through Oct-1 and VP16 corecruitment. Genes \& Dev. 7: 72-83.

Curran, T. and B.R. Franza Jr. 1988. Fos and Jun: The AP-1 connection. Cell 55: 395-397.

Dale, T.C., J.M. Rosen, M.S. Guille, A.R. Lewin, A.C.G. Porter, I.M. Kerr, and G.R. Stark. 1989. Overlapping sites for constitutive and induced DNA-binding factors involved in interferon-stimulated transcription. EMBO /. 8: 831-839.

Fields, S. and O. Song. 1989. A novel genetic system to detect protein-protein interactions. Nature 340: 245-246.

Forsburg, S.L. and L. Guarente. 1989. Identification and characterization of HAP4: A third component of the CCAATbound HAP2/HAP3 heteromer. Genes \& Dev. 3: 1166-1178.

Fu, X.Y., D.S. Kessler, S.A. Veals, D.E. Levy, and J. Darnell. 1990. ISGF-3, the transcriptional activator induced by interferon $\alpha$, consists of multiple interacting polypeptide chains. Proc. Natl. Acad. Sci. 87: 8555-8559.

Gerster, T. and R.G. Roeder. 1988. A herpes virus trans-activating protein interacts with transcriptional factor OTF-1 and other cellular proteins. Proc. Natl. Acad. Sci. 85: 6347-6351.

Gietz, D., A. St. Jean, R.A. Woods, and R.H. Schiestl. 1992. Improved method for high efficiency transformation of intact yeast cells. Nucleic Acids Res. 20: 1425.

Guan, K.L. and J.E. Dixon. 1991. Eukaryotic proteins expressed in $E$. coli: An improved thrombin cleavage and purification procedure of fusion proteins with glutathione S-transferase. Anal. Biochem. 192: 202-267.

Guarente, L. 1983. Yeast promoters and lacZ fusions designed to study expression of cloned genes in yeast. Methods Enzymol. 101: 181-191.

Guarente, L. and T. Mason. 1983. Heme regulates transcription of the CYC1 gene of $S$. cerevisiae via an upstream activation site. Cell 32: 1279-1286.

Guarente, L., B. Lalonde, P. Gifford, and E. Alani. 1984. Distinctly regulated tandem upstream activation sites mediate catabolite repression of the CYC1 gene of $S$. cerevisiae. Cell 36: 503-511.

Gyuris, J., E. Golemis, H. Chertkov, and R. Brent. 1993. Cdi1, a human G1 and S phase protein phosphatase that associates with Cdk2. Cell 75: 791-803.

Hahn, S. and L. Guarente. 1988. Yeast HAP2 and HAP3: Transcriptional activators in a heteromeric complex. Science 240: $317-321$

Hahn, S., J. Pinkham, R. Wei, R. Miller, and L. Guarente. 1988. The HAP3 regulatory locus of Saccharomyces cerevisiae encodes divergent overlapping transcripts. Mol. Cell. Biol. 8: 655-663.

Hoffman, C.S. and F. Winston. 1987. A ten minute DNA preparation for yeast efficiently releases autonomous plasmids for transformation of E. coli. Gene 57: 267-272.

Hooft van Huijsduijnen, R., X.Y. Li, D. Black, H. Matthes, C. Benoist, and D. Mathis. 1990. Co-evolution from yeast to mouse: cDNA cloning of the two NF-Y $(\mathrm{CP} 1 / \mathrm{CBF})$ subunits. EMBO J. 9: 3119-3127.

Kaelin Jr., W.G., D.C. Palias, J.A. DeCaprio, F.J. Kaye, and D.M. Livingston. 1991. Identification of cellular proteins that can interact specifically with the T/E1A-binding region of the retinoblastoma gene product. Cell 64: 521-532.

Katan, M., A. Haigh, C.P. Verrijzer, P.C. van der Vliet, and P. O'Hare. 1990. Characterization of a cellular factor which interacts functionally with Oct-1 in the assembly of a multicomponent transcription complex. Nucleic Acids Res. 18: $6871-6880$

Kessler, D.S., D.E. Levy, and J. Darnell. 1988. Two interferon- induced nuclear factors bind a single promoter element in interferon-stimulated genes. Proc. Natl. Acad. Sci. 85: 85218525.

Kessler, D.S., S.A. Veals, X.Y. Fu, and D.E. Levy. 1990. Interferon- $\alpha$ regulates nuclear translocation and DNA-binding affinity of ISGF-3, a multimeric transcriptional activator. Genes \& Dev. 4: 1753-1765.

Kristie, T.M. and P.A. Sharp. 1990. Interactions of the Oct-1 POU subdomains with specific DNA sequences and with the HSV $\alpha$-trans-activator protein. Genes \& Dev. 4: 23832396.

Kristie, T.M., J.H. LeBowitz, and P.A. Sharp. 1989. The octamerbinding proteins form multi-protein-DNA complexes with the HSV $\alpha$ TIF regulatory protein. EMBO $7.8: 4229-4238$.

LaMarco, K.L. and S.L. McKnight. 1989. Purification of a set of cellular polypeptides that bind to the purine-rich cis-regulatory element of herpes simplex virus immediate early genes. Genes \& Dev. 3: 1372-1383.

Landschulz, W.H., P.F. Johnson, and S.L. McKnight. 1988. The leucine zipper: A hypothetical structure common to a new class of DNA binding proteins. Science 240: 1759-1764.

Levy, D.E., D.S. Kessler, R. Pine, N. Reich, and J. Darnell. 1988. Interferon-induced nuclear factors that bind a shared promoter element correlate with positive and negative control. Genes \& Dev. 2: 383-393.

Levy, D.E., D.S. Kessler, R. Pine, and J. Darnell. 1989. Cytoplasmic activation of ISGF-3, the positive regulator of interferon$\alpha$-stimulated transcription, reconstituted in vitro. Genes \& Dev. 3: 1362-1371.

Li, X.Y., R. Mantovani, R. Hooft van Huijsduijnen, I. Andre, C. Benoist, and D. Mathis. 1992. Evolutionary variation of the CCAAT-binding transcription factor NF-Y. Nucleic Acids Res. 20: 1087-1091.

Maity, S.N. and B. de Crombrugghe. 1992. Biochemical analysis of the B subunit of the heteromeric CCAAT-binding factor. J. Biol. Chem. 267: 8286-8292.

Maity, S.N., T. Vuorio, and B. de Crombrugghe. 1990. The B subunit of a rat heteromeric CCAAT-binding transcription factor shows striking sequence identity with the yeast Hap2 transcription factor. Proc. Natl. Acad. Sci. 87: 5378-5382.

Maity, S.N., S. Sinha, E.C. Ruteshouser, and B. de Crombrugghe. 1992. Three different polypeptides are necessary for DNA binding of the mammalian heteromeric CCAAT binding factor. J. Biol. Chem. 267: 16574-16580.

McKnight, J.L.C., T.M. Kristie, and B. Roizman. 1987. Binding of the virion protein mediating $\alpha$ gene induction in herpes simplex virus 1 -infected cells to its cis site requires cellular proteins. Proc. Nat1. Acad. Sci. 84: 7061-7065.

Murre, C., P.S. McCaw, H. Vaessin, M. Caudy, L.Y. Jan, Y.N. Jan, C.V. Cabrera, J.N. Buskin, S.D. Hauschka, A.B. Lassar, H. Weintraub, and D. Baltimore. 1989. Interactions between heterologous helix-loop-helix proteins generate complexes that bind specifically to a common DNA sequence. Cell 58: $537-544$

O'Hare, P. and C.R. Goding. 1988. Herpes simplex virus regulatory elements and the immunoglobulin octamer domain bind a common factor and are both targets for virion transactivation. Cell 52: 435-445.

Olesen, J.T. and L. Guarente. 1990. The HAP2 subunit of yeast CCAAT transcriptional activator contains adjacent domains for subunit association and DNA recognition: Model for the HAP2/3/4 complex. Genes \& Dev. 4: 1714-1729.

Olesen, J., S. Hahn, and L. Guarente. 1987. Yeast HAP2 and HAP3 activators both bind to the $C Y C 1$ upstream activation site, UAS2, in an interdependent manner. Cell 51: 953-961.

Olesen, J.T., J.D. Fikes, and L. Guarente. 1991. The Schizosac- 
charomyces pombe homolog of Saccharomyces cerevisiae HAP2 reveals selective and stringent conservation of the small essential core protein domain. Mol. Cell. Biol. 11: 611-619.

Pinkham, J.L. and L. Guarente. 1985. Cloning and molecular analysis of the HAP2 locus: A global regulator of respiratory genes in Saccharomyces cerevisiae. Mol. Cell. Biol. 5: 34103416.

Pinkham, J.L., J.T. Olesen, and L.P. Guarente. 1987. Sequence and nuclear localization of the Saccharomyces cerevisiae HAP2 protein, a transcriptional activator. Mol. Cell. Biol. 7: $578-585$.

Preston, C.M., M.C. Frame, and M.E.M. Campbell. 1988. A complex formed between cell components and an HSV structural polypeptide binds to a viral immunoglobulin early gene regulatory sequence. Cell 52: 425-434.

Riles, L., J.E. Dutchik, A. Baktha, B.K. McCauley, E.C. Thayer, M.P. Leckie, V.V. Braden, J.E. Depke, and M.V. Olson. 1993. Physical maps of the six smallest chromosomes of Saccharomyces cerevisiae at a resolution of 2.6 kilobase pairs. Genetics 134: 81-150.

Sanger, F., S. Nicklen, and A.R. Coulson. 1977. DNA sequencing with chain-terminating inhibitors. Proc. Natl. Acad. Sci. 74: 5463-5467.

Sherman, F. 1991. Getting started with yeast. Methods Enzy. mol. 194: 3-21.

Sikorski, R.S. and J.D. Boeke. 1991. In vitro mutagenesis and plasmid shuffling: From cloned gene to mutant yeast. Methods Enzymol. 194: 302-318.

Sikorski, R.S. and P. Hieter. 1989. A system of shuttle vectors and yeast host strains designed for efficient manipulation of DNA in Saccharomyces cerevisiae. Genetics 122: 19-27.

Smith, D.B. and K.S. Johnson. 1988. Single-step purification of polypeptides expressed in Escherichia coli as fusions with glutathione S-transferase. Gene 67: 31-40.

Stern, S. and W. Herr. 1991. The herpes simplex virus transactivator VP16 recognizes the Oct-1 homeo domain: Evidence for a homeo domain recognition subdomain. Genes \& Dev. 5: 2555-2566.

Tartof, K.D. and C.A. Hobbs. 1987. Improved media for growing plasmid and cosmid clones. Bethesda Res. Lab. Focus 9: 12.

Thompson, C.C., T.A. Brown, and S.L. McKnight. 1991. Convergence of Ets- and Notch-related structural motifs in a heteromeric DNA binding complex. Science 253: 762-768.

Thompson, C.M., A.J. Koleske, D.M. Chao, and R.A. Young. 1993. A multisubunit complex associated with the RNA polymerase II CTD and TATA-binding protein in yeast. Cell 73: $1361-1375$.

Triezenberg, S.J., K.L. LaMarco, and S.L. McKnight. 1988. Evidence of DNA:protein interactions that mediate HSV-1 immediate early gene activation by VP16. Genes \& Dev. 2: 730-742.

Vuorio, T., S.N. Maity, and B. de Crombrugghe. 1990. Purification and molecular cloning of the " $\mathrm{A}$ " chain of a rat heteromeric CCAAT-binding protein. Sequence identity with the yeast HAP3 transcription factor. I. Biol. Chem. 265: 2248022486.

Wang, S. and N.A. Speck. 1992. Purification of core-binding factor, a protein that binds the conserved core site in murine leukemia virus enhancers. Mol. Cell. Biol. 12: 89-102.

Wang, S., Q. Wang, B.E. Crute, I.N. Melnikova, S.R. Keller, and N.A. Speck. 1993. Cloning and characterization of subunits of the T-cell receptor and murine leukemia virus enhancer core-binding factor. Mol. Cell. Biol. 13: 3324-3339.

Xiao, P. and J.P. Capone. 1990. A cellular factor binds to the herpes simplex virus type 1 trans-activator Vmw65 and is required for Vmw65-dependent protein-DNA complex assembly with Oct-1. Mol. Cell. Biol. 10: 4974-4977.

Xing, Y., J.D. Fikes, and L. Guarente. 1993. Mutations in yeast HAP2/HAP3 define a hybrid CCAAT box binding domain. EMBO J. 12: 4647-4655.

Xing, Y., S. Zhang, J.T. Olesen, A. Rich, and L. Guarente. 1994. Subunit interaction in the CCAAT-binding heteromeric complex is mediated by a very short $\alpha$-helix in HAP2. Proc. Natl. Acad. Sci. 91: 3009-3013.

Zervos, A.S., J. Gyuris, and R. Brent. 1993. Mxil, a protein that specifically interacts with Max to bind Myc-Max recognition sites. Cell 72: 223-232. 


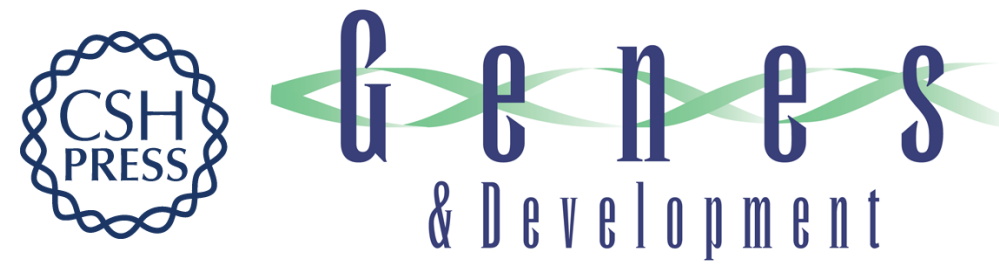

\section{Cloning of yeast HAP5: a novel subunit of a heterotrimeric complex required for CCAAT binding.}

D S McNabb, Y Xing and L Guarente

Genes Dev. 1995, 9:

Access the most recent version at doi:10.1101/gad.9.1.47

References This article cites 63 articles, 34 of which can be accessed free at:

http://genesdev.cshlp.org/content/9/1/47.full.html\#ref-list-1

License

Email Alerting

Service right corner of the article or click here.

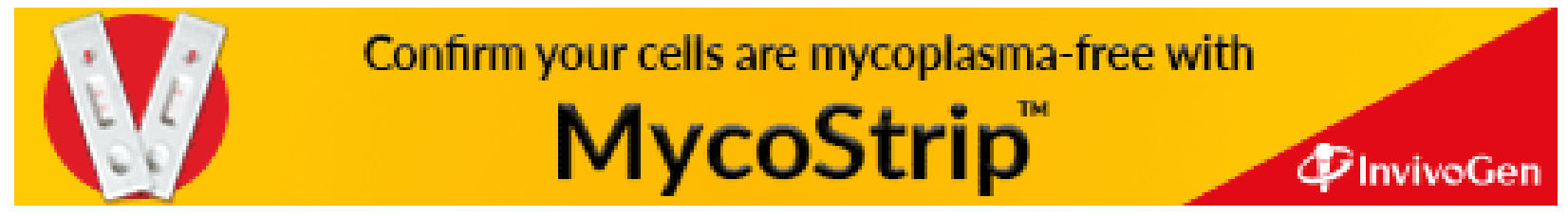

